\title{
Rail Transit Development of the Pearl River Delta Planning, Obstacles and History
}

\author{
Bin Chen ${ }^{1}$ (iD
}

Received: 30 December 2016/Revised: 23 October 2017/Accepted: 27 December 2017/Published online: 18 January 2018

(C) The Author(s) 2018. This article is an open access publication

\begin{abstract}
A new round of regional planning was conducted from 2014 to 2016 by the provincial government of Guangdong, providing an overview of the regional transportation development and history. Major problems in the Pearl River Delta (PRD) railway network are identified: the inconsistencies between railway planning and land use, lack of transitoriented regional policy, issues regarding the competition and compatibility of different methods of transportation by rail. This paper incorporates the following solutions which include direct connection of major regional business centers, improve railway and land use synergy, integrate railway and underground subway system and also discusses the future of railway transportation in densely populated areas.
\end{abstract}

Keywords Pearl River Delta (PRD) - Rail Transit

Planning · Intercity Transportation · Megacity

\section{Introduction}

With the rapid development of urban rail transit and intercity railways, rail transit has played an increasingly important role in shaping the urban and transportation landscape of China's densely populated regions. The Pearl

Bin Chen: Regional Planner and Transport Modeler 2005-2009, North Central Texas Council of Governments, USA.

Bin Chen

8151862@qq.com

1 Guangdong Housing and Urban Rural Construction Department, Policy Research Center, No. 483 Nanzhou Road, Guangzhou 510290, People's Republic of China

Editor: Xuesong Zhou.
River Delta (PRD), located in South China, covers an area of $54,754 \mathrm{~km}^{2}$, has a population of 57.15 million and per capita GDP of about $\$ 15,000$. Since 1990 , there have been four major regional planning sessions in the PRD region, conducted, respectively, in 1994, 2004, 2008 and 2014. From May 2014 to December 2016, a new round of regional planning [1] was carried out with the guidance of the Guangdong provincial government, and the major encountered problem was the railway network planning.

Large scale railway and subway networks are being planned and built in the PRD. To support the new round of planning, we utilized big data gathered from cell phones to analyze and determine the connectivity of city pairs. The integration of rail and subway networks is especially important in the PRD area as the cities are located in close proximity to each other; however, the required time in order to build a system of such scale is long and demanding.

\section{Transport Development and History in the PRD}

The early urban expansion of PRD was mainly due to the development of an export-oriented economy and the building of freeways and arterial roadways, as shown in Fig. 1. The urban development in the PRD continues to expand with the development of freeway systems, starting from the early 1990s.

Simultaneously, a large number of people migrated from the inland to the PRD. The population increased by a total of 14.25 million people from 2000 to 2013 . The population density is unevenly distributed, and thus Guangzhou and Shenzhen have the highest concentration, as shown in Fig. 2.

Intercity express railways operated regularly between Guangzhou and Shenzhen as early as 2011. The total railway length is about $2192 \mathrm{~km}$, while the railway density 


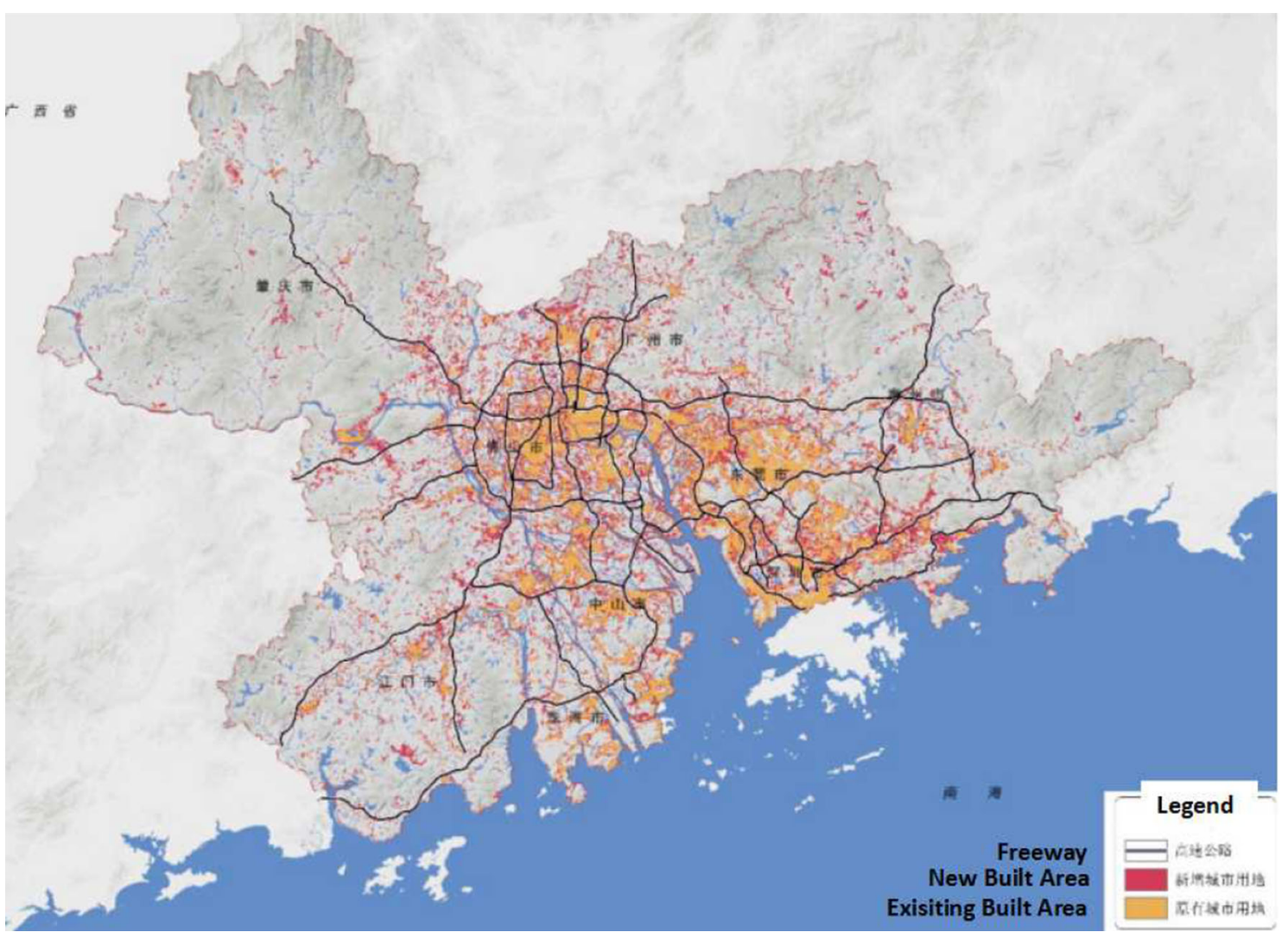

Fig. 1 Freeway development and built area change 2005-2010

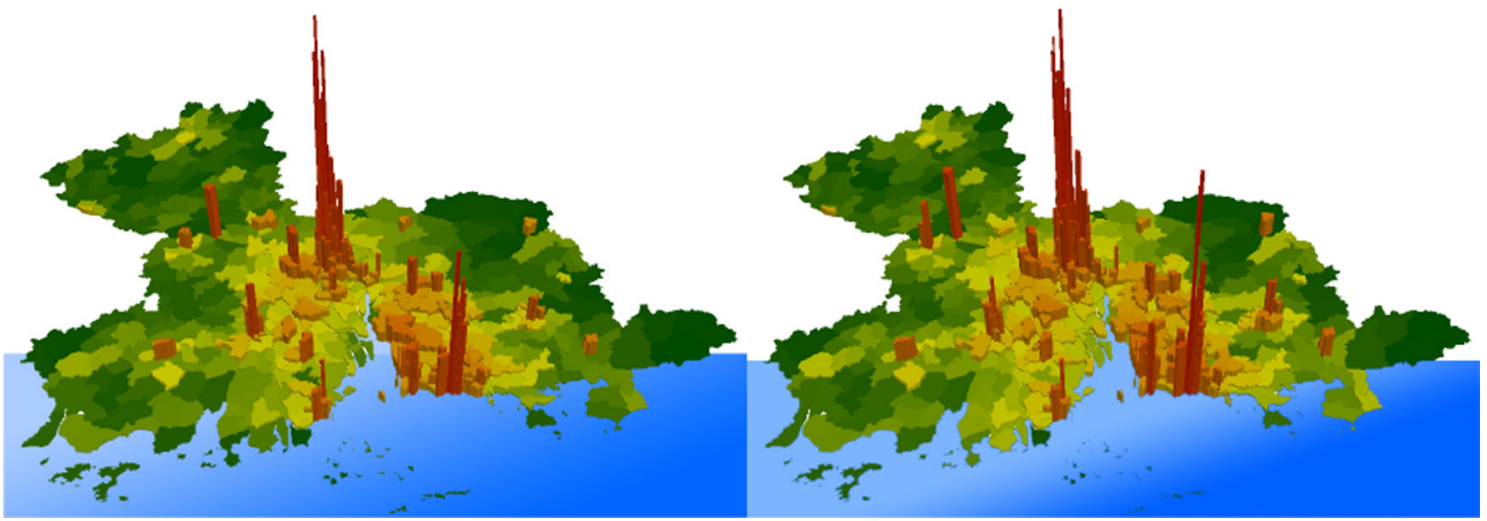

Fig. 2 Population density of PRD in 2000 and 2010 (census data) [2]

Table 1 Regional Railway Comparison

\begin{tabular}{lllll}
\hline & PRD & Tokyo Metro & Yangtze River Delta & Beijing-Tianjin-Hebei \\
\hline Rail $(\mathrm{km})$ & 2192 & 2894 & 4570 & 8700 \\
Area $\left(10,000 \mathrm{~km}^{2}\right)$ & 5.5 & 1.34 & 21.1 & 19.1 \\
Rail density $\left(\mathrm{km} / 100 \mathrm{~km}^{2}\right)$ & 4 & 21.6 & 2.17 & 4 \\
\hline
\end{tabular}

is close to the existing density in Beijing-Tianjin-Hebei area, but is about $1 / 5$ of the density in Tokyo metropolitan areas. (Table 1). Figure 3 shows the current railway system in the PRD region, and indicates that Guangzhou is at the center of the railway network, with data from the Guangzhou-shenzhen, Guangzhou-zhuhai intercity railway and several other long-distance high-speed lines. 


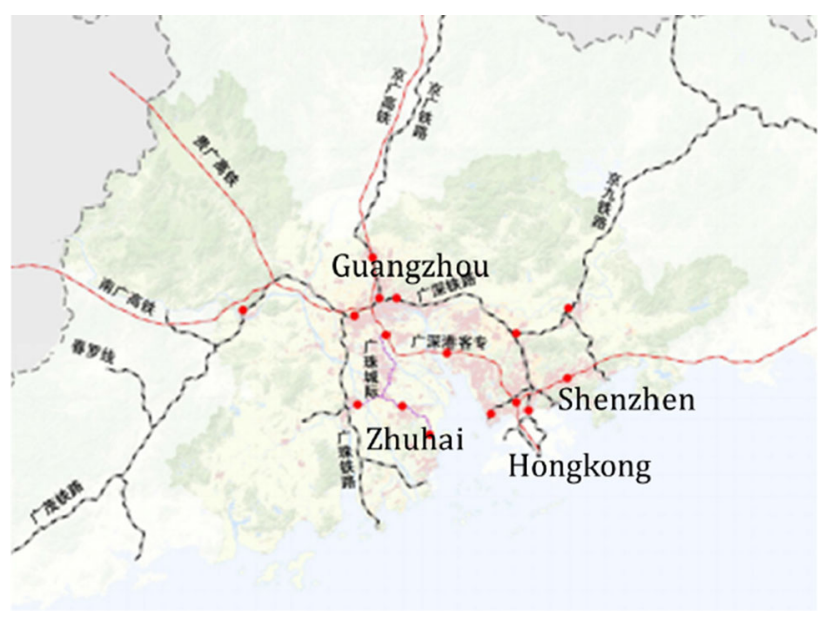

Fig. 3 Current railway system in PRD

To fully understand the impact of the new transport technology on the development of the area, it is important to look at the history of the local transportation development. The PRD area has a long history of water transportation, but changed dramatically with the advent of large river-crossing bridges. In 1988, Guangzhou opened the first bridge that crosses the south channel of the Pearl River between Guangzhou and Panyu (now a district of Guangzhou), and from the year 2000, we have seen a rapid development of freeways and vehicle transportations. Jesse H. Ausubel [3] has defined the evolution of transportation mode in the USA as a process of growth and mode transformation [3]. He defines the growth of a particular transport mode (technology) as following a parabolic function, and observes that each form has three important stages with respect to time: the time of mode change, the time of construction peak, the time of full maturity. As China is comparable in land area and economic scale to the USA and is undergoing rapid economic changes, the transportation evolution could also follow similar development cycles and curves. Here the development of PRD

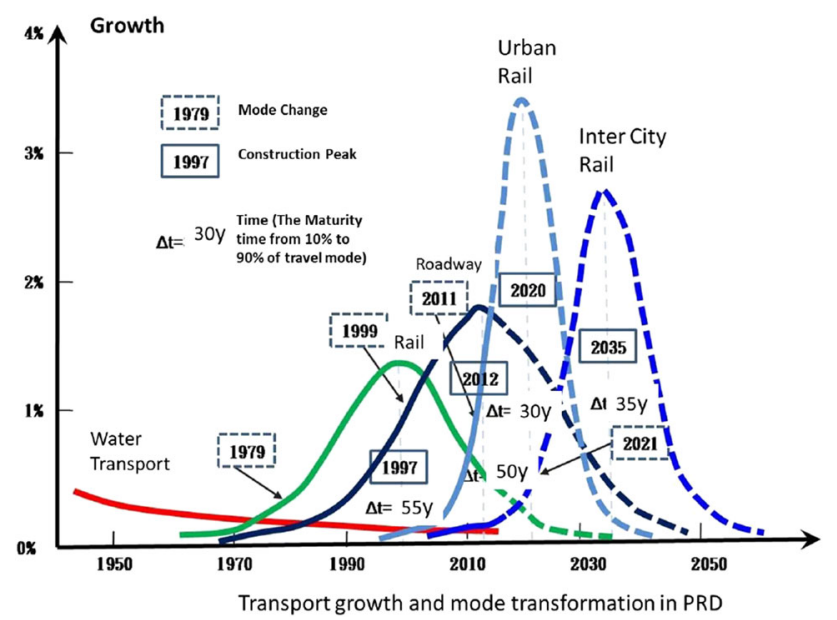

Fig. 4 PRD transport mode change over time (Author) transportation is used as an example. As shown in Fig. 4, we define $\Delta t$ as the time it takes for a particular transportation method to reach full maturity at $90 \%$, with the rate of change increasing, from a time of 50 years for rail to close to 30 years for urban rail. The year marking the watershed year is determined by the initiation of an important project, such as a major bridge, freeway or railway line. In the PRD area, the two major cities of Guangzhou and Shenzhen are building urban subway systems at a faster pace and are projected to gain an extensive urban metro system built by the year 2020 . However, the construction period of the intercity railway could require more time, and since it is currently at an early experimental stage, major changes will not be seen until approximately 2021 or later depending on the project development schedule. The development of an intercity railway network has high expectations but faces more uncertainty (profitability, land reclamation, political, operational, etc.), and this should be considered when conducting regional planning in the PRD. This is significant because it emphasizes on the aspect of time in planning, the anticipated changes as well as the adjustments and actions needed to meet the transport demands at different stages.

Currently, the roadway transportation including private vehicles and intercity buses dominates the regional transport in PRD. In order to facilitate changes in transportation modes and support the sustainable development of rail transit networks in the region, governments should set up a policy to discourage the use of private cars and allocate more resources and priorities on public transit, especially urban rails and intercity railways, to make the transition more efficient and sustainable.

\section{Problems Regarding Intercity Railway Planning}

The "Pearl River Delta Intercity Railway Network Plan," approved in 2009 by the national government, envisions an intercity rail network of $1478 \mathrm{~km}$ and 16 lines, centered in Guangzhou, the capital of Guangdong province and connects to other major cities in the region (Fig. 5).

The intercity railway plan of the PRD has undergone years of consultation and several rounds of amendments, and the construction of several lines are already under way, but is pending due to another round of modifications, depending on the operation of the first lines. From a planning perspective, three possible problems have been identified, and the corresponding planning measures or changes were proposed.

(1) The first problem is that the planned regional railway networks deviate from the current travel and commuting patterns and is not well connected with the regional work and commercial centers. 


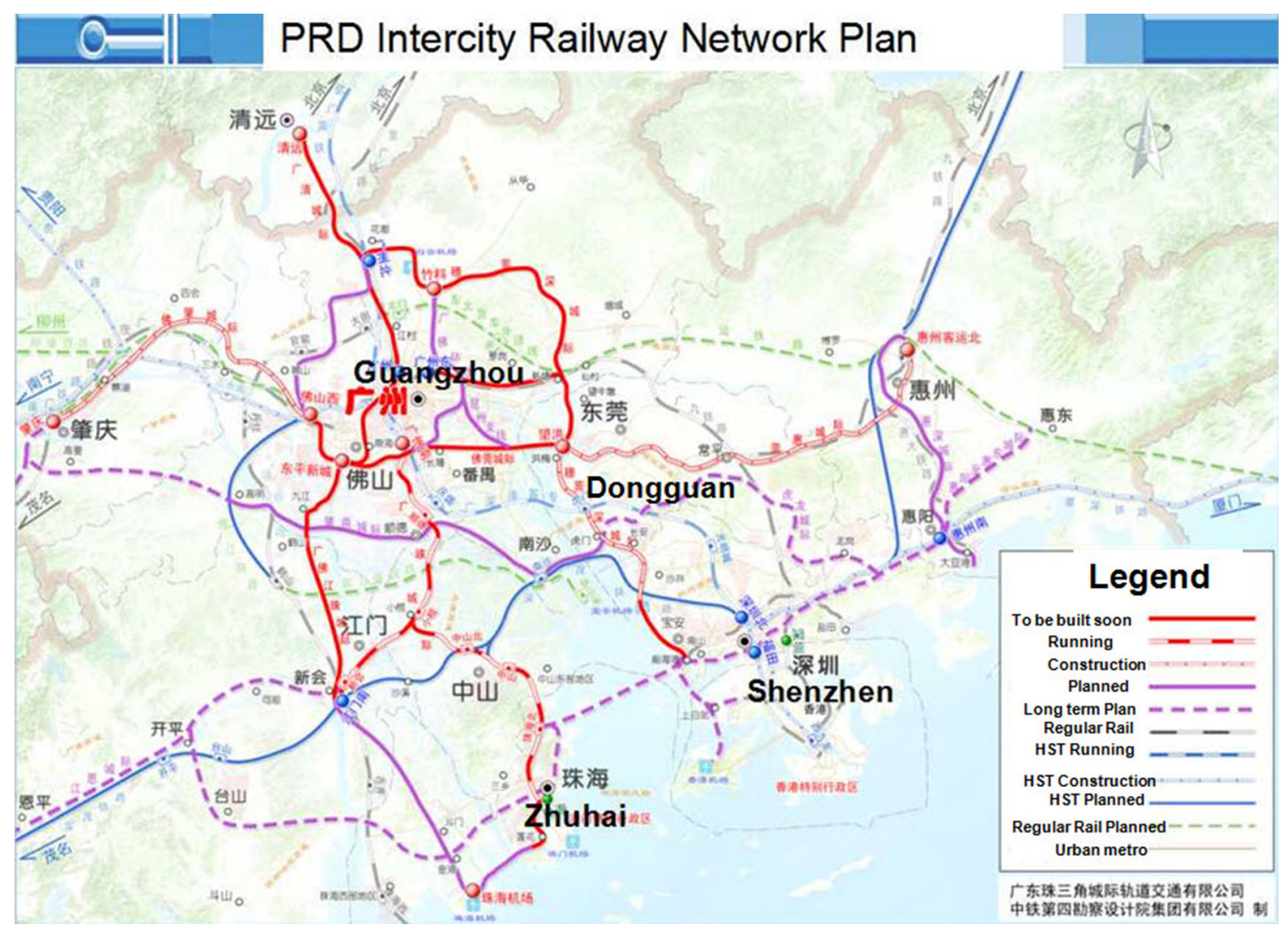

Fig. 5 PRD intercity railway network plan

The plan has drawn a lot of criticism and controversies over the years, with non-technical aspects also affecting the railway routing. Major issues include:

1. Shenzhen needs more direct connection to other cities (Huizhou, Dongguan, and Zhaoqing, etc.). As a major production and economic center in the PRD, Shenzhen does not have enough railway connection to match its economic scale. The current network planning is still solely centered around one city, Guangzhou.

2. There is a lack of emphasis on radial lines connecting regional business centers which conform to the current commuting pattern, and there is no commuter railway plan for the region. As we can see from the railway network of Tokyo (Fig. 6), it has more than 20 lines "radiating out" from the Yamanote circle line, which basically defines the main city center and business centers of Tokyo.

3. There is a lack of consideration on land use synergy or land development strategy. The connection to regional airports and major railway stations is strong, but not to the regional employment centers. Based on the observation and theory of mode choice, intercity rail service is more sensitive to the service level, the high density resulting from the merge with long-distance travelers correlates to less enthusiasm for intercity travels.
2. The second problem is the lack of a strong transitoriented policy, railway stations and new land development are not in synchronization [4]. The first line of the PRD intercity railway, Guangzhou-Zhuhai intercity express opened in January 2011, since then the ridership has seen a steady rise of $23 \%$ annually (Fig. 7), but there is also an anomaly in the two stations of Jiangmen and Xinhui, which encountered a decline of passengers in 2013. This reflects the competition with other transport, especially from the expressway systems; upon further investigation and local interviews, the reason is that the two stations are located on the fringe of the city to the south, while the city's new development area is in the north of the old city. (The volume from Zhuhaibei moved to Zhuhai station after the opening of new businesses in 2013.)

3. The third problem is the competing interests of different lines in the same corridor, which calls for better coordination and integration. The competition between high-speed trains, intercity trains and subway lines could lead to over-construction and problems affecting sustainability. For example, between Guangzhou and Shenzhen (Fig. 8), there are at least four different modes of rail, including the Guangzhou-Shenzhen railway, the GZ-SZ-HK high-speed rail and the 


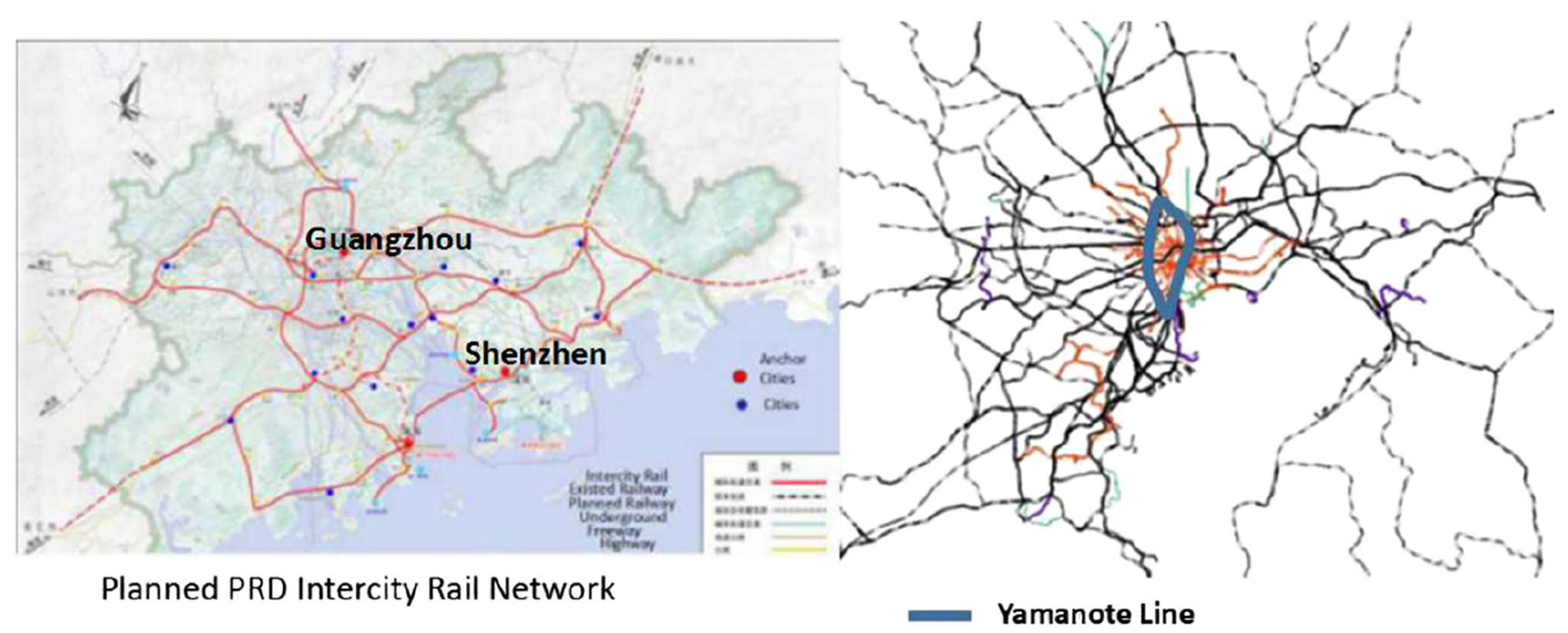

Tokyo Metro Area Rail Network

Fig. 6 Intercity railway network planning in PRD and comparison with Tokyo area

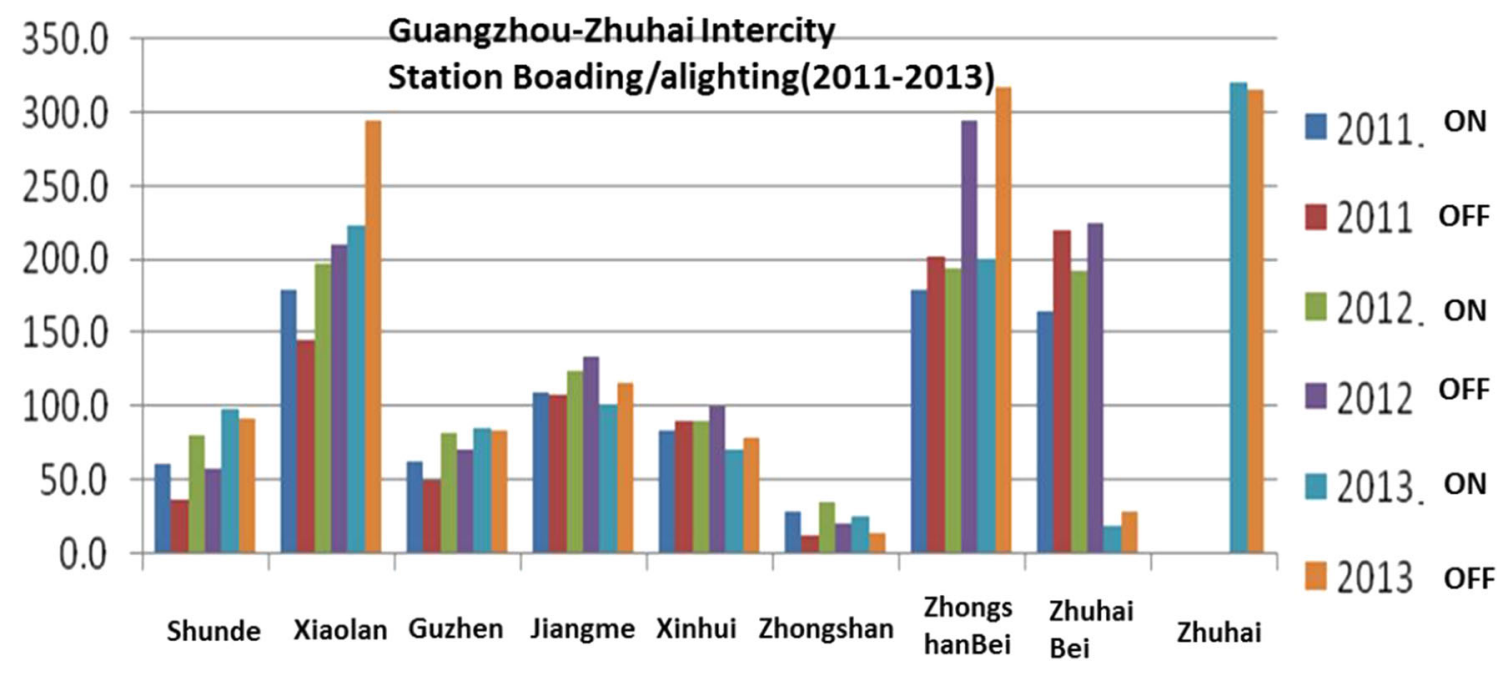

Fig. 7 Ridership changes of Guangzhou-Zhuhai intercity railway

Fig. 8 Competing railway lines between Guangzhou and Shenzhen

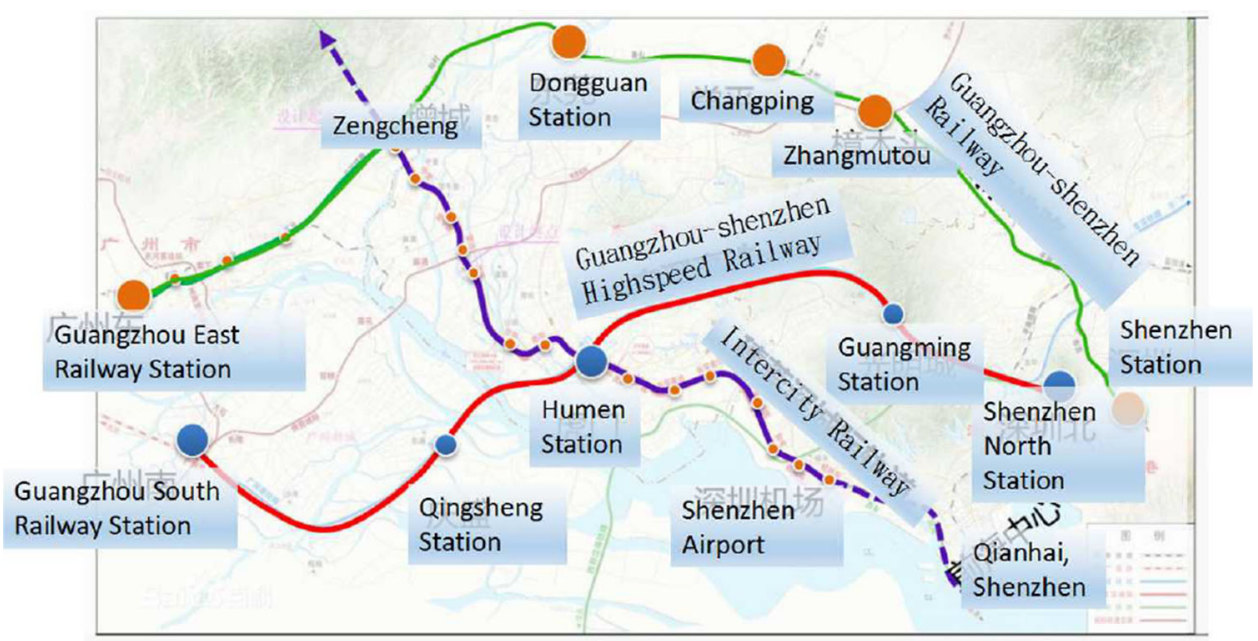


intercity rail. There are also several planned subway lines connecting the cities of Guangzhou and Shenzhen.

Guangzhou and Shenzhen, the two largest cities in the PRD, are both building a world-class subway system. (Both are planning subway networks with total lengths exceeding $1000 \mathrm{~km}$, while the largest urban metro network in a country other than China is London's $461 \mathrm{~km}$.) The latest rail and subway system map of the PRD is drawn (existing and planned) in Fig. 9. In order to create a better geographic sense in the map, freeways of the region are also shown in the background. Two rail-intensive areas are the Guangzhou-Foshan region and Shenzhen. Examining the Guangzhou-Foshan metropolitan area, there will be more than 10 subway lines connecting the two cities in operation, in addition, there will also be a Guangzhou-Foshan Ring Railway which connects to the Guangzhou Airport and Guangzhou South Railway Station to provide service to both cities (Fig. 10). The infrastructure will turn Guangzhou-Foshan into a megacity, which will be competitive with the scale of Beijing and Shanghai. The main problem is the possible competition between the two systems, subway and intercity rail, which are in the same corridor occasionally, yet these two systems are not compatible with each other and have different design specifications.

\section{Regional Travel Pattern in PRD Analyzed by Big Data}

Using cell phone signal data during a period of about 2 weeks in Dec. 2015 [1], we analyzed the personal movement (flow) of city pairs in the Pearl River Delta area, as
Fig. 11 shows, Guangzhou and Foshan have the strongest link and personal exchanges. The next tier is between city pairs of Guangzhou-Dongguan, Shenzhen-Dongguan and Shenzhen-Huizhou, and this reflects the status quo of major transport corridors in the region. While GuangzhouFoshan provides subway trains that operate every $5 \mathrm{~min}$, there is no planned direct connection from Shenzhen to Dongguan or Huizhou. Also from the map, there is a very weak connection between cities on the east of the Pearl River Delta and those on the west, and this is partly due to the slow progress of the Pearl-river-crossing bridges. The regional travel demand is also shown in Fig. 12 as an estimate of combining travel survey, data, and local information. In such a fast developing area as the Pearl River Delta, data are a scarce resource, but with the help of cell phone companies and computers we can conduct a quick analysis.

\section{Solutions Toward Building a Sustainable Network Connecting the Region}

\subsection{Direct Connection High Density Areas in the PRD}

According to Walter Christaller's Central Place Theory, geographic patterns of human settlements form different orders or hierarchy of centers. Peter J. Taylor, the researcher of world city, explained the importance of network flows and advocated the use of "Central Place + Central Flow Theory" [5]. The most important regional

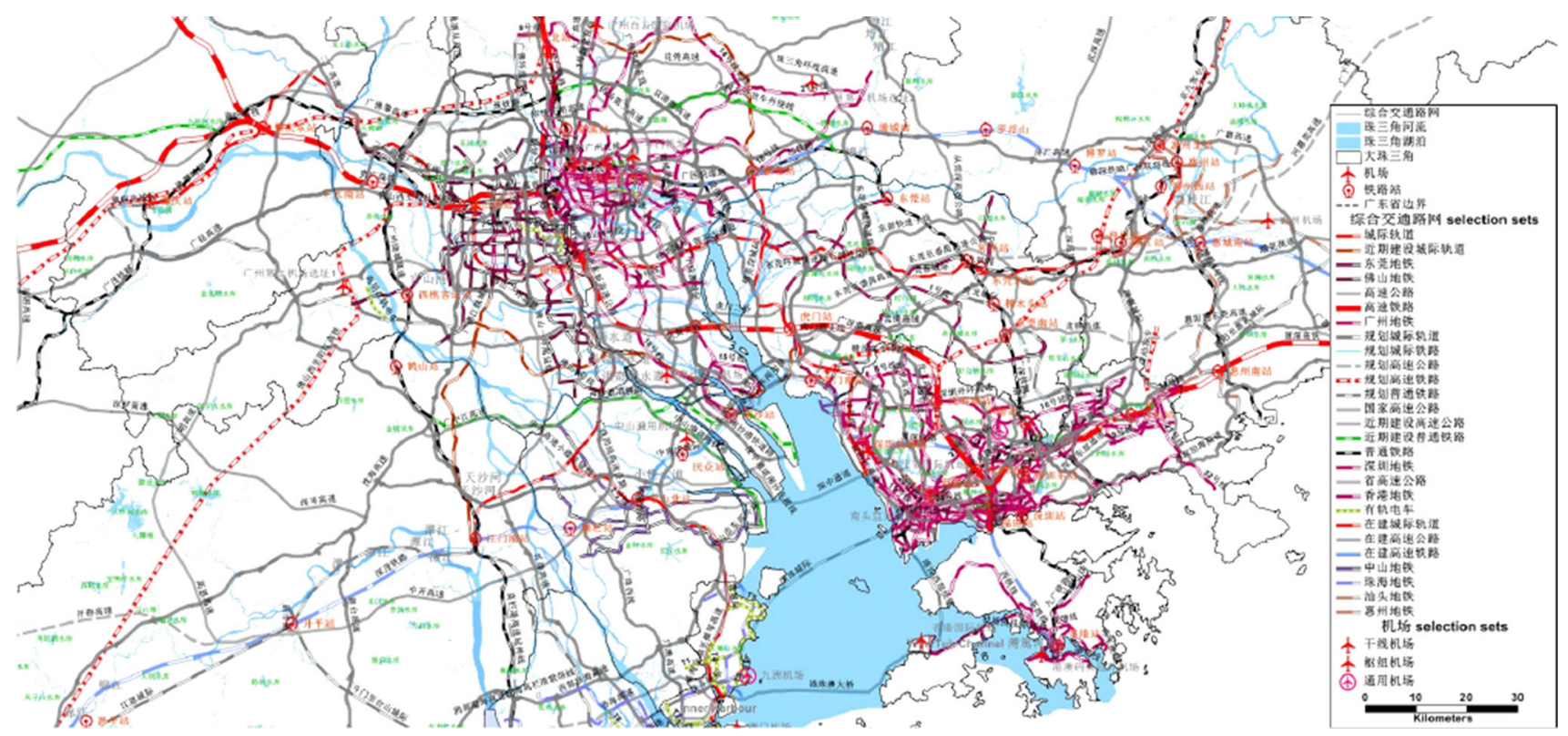

Fig. 9 PRD rail and subway system map 


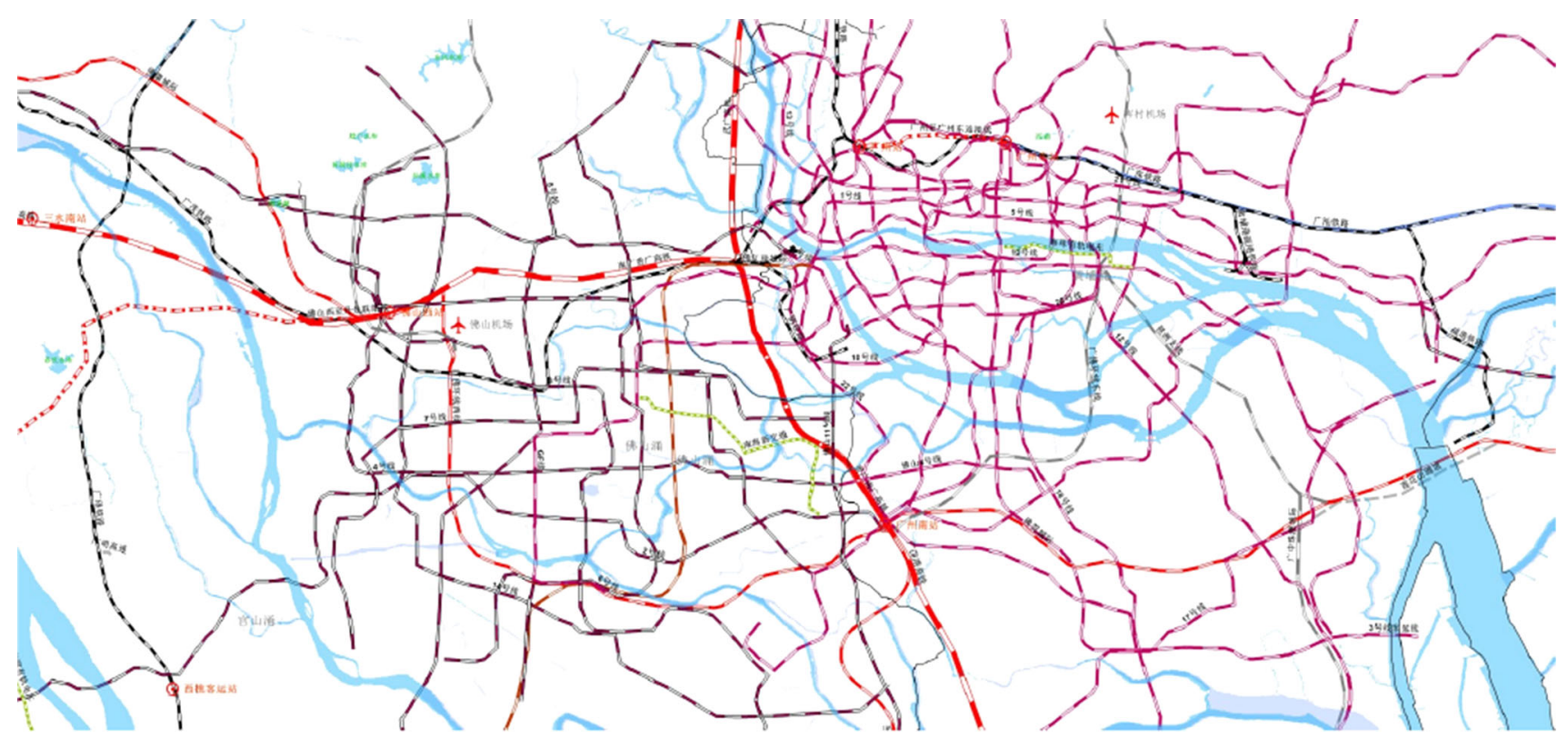

Fig. 10 Guangzhou-Foshan metropolitan area rail map (author)

Fig. 11 Person traffic between PRD cities using cell phone data

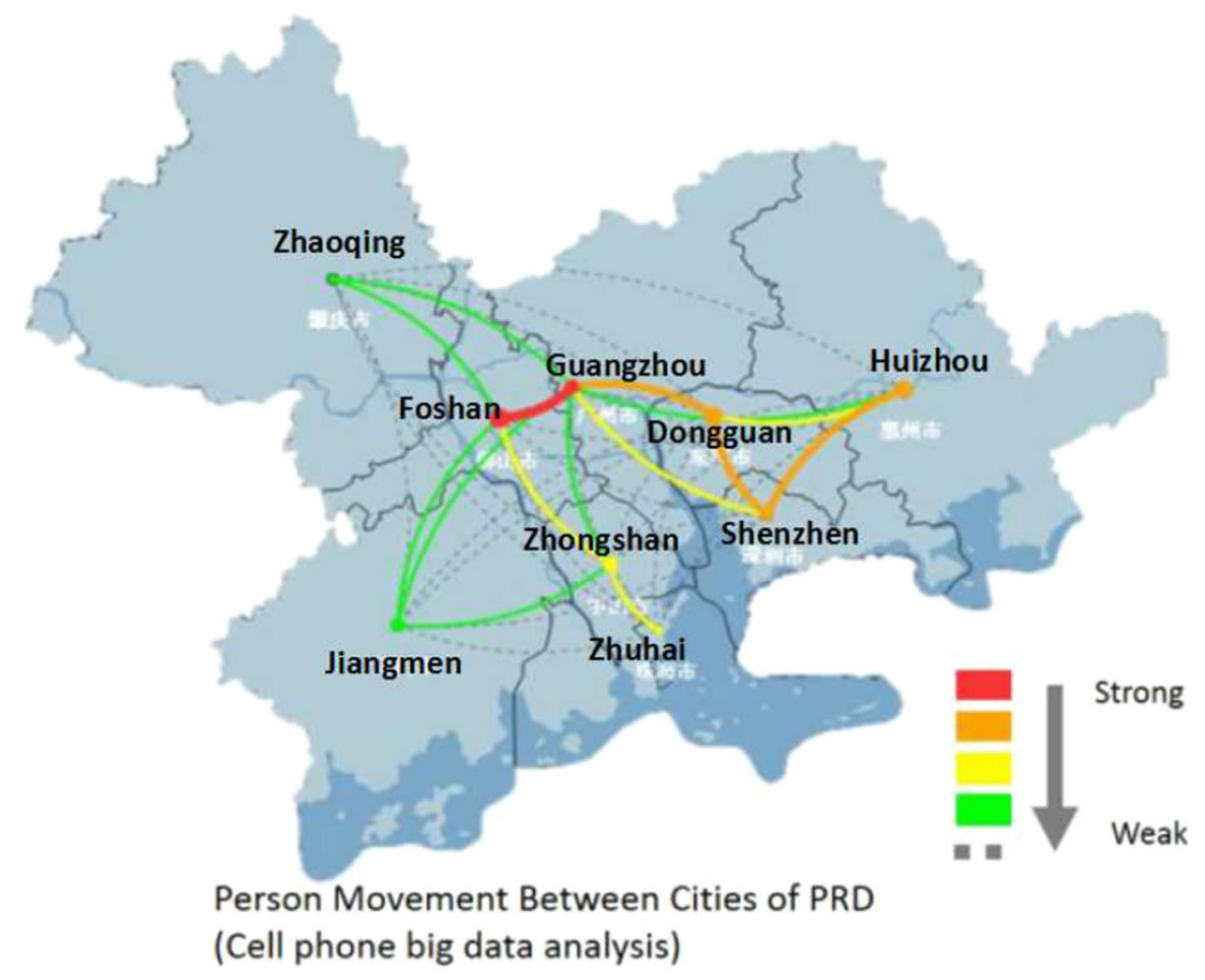

centers also require direct and higher speed connections, and this will support the development of the service and headquarter centers and will make rail transit more business friendly and sustainable. Figure 13 shows the major regional centers in the PRD connected through a highspeed railway system. One way to connect major financial or business centers in the greater PRD is illustrated in
Fig. 14. The direct link of Futian CBD of Shenzhen and Kowloon CBD of Hongkong is achieved by GZ-SZ-HK high-speed rail, to strengthen the connection to the business centers of Guangzhou (Zhujiang New Town and International Finance Center), a direct PRD Business Express Rail system is planned and shown in the graph. 
Fig. 12 Travel demand estimate of PRD region

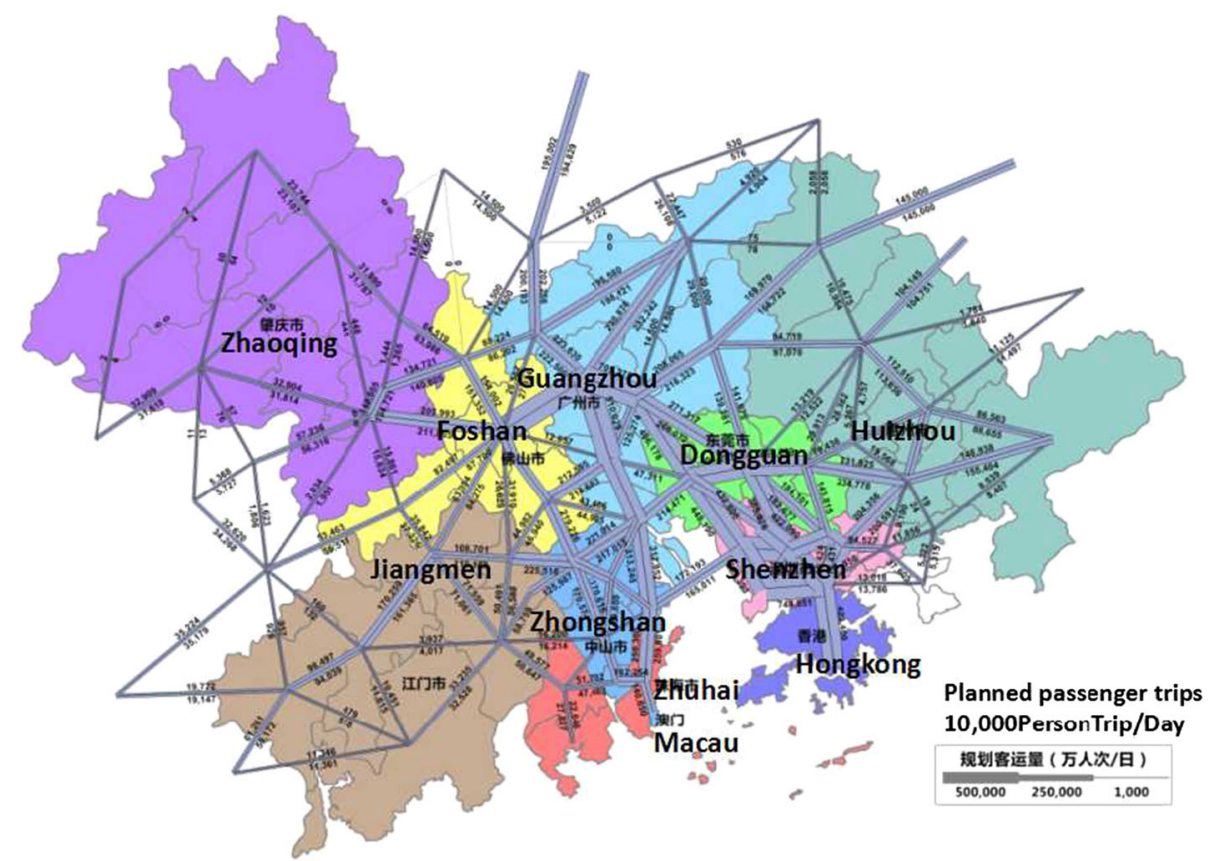

Fig. 13 Intercity railways that connects major regional centers of PRD

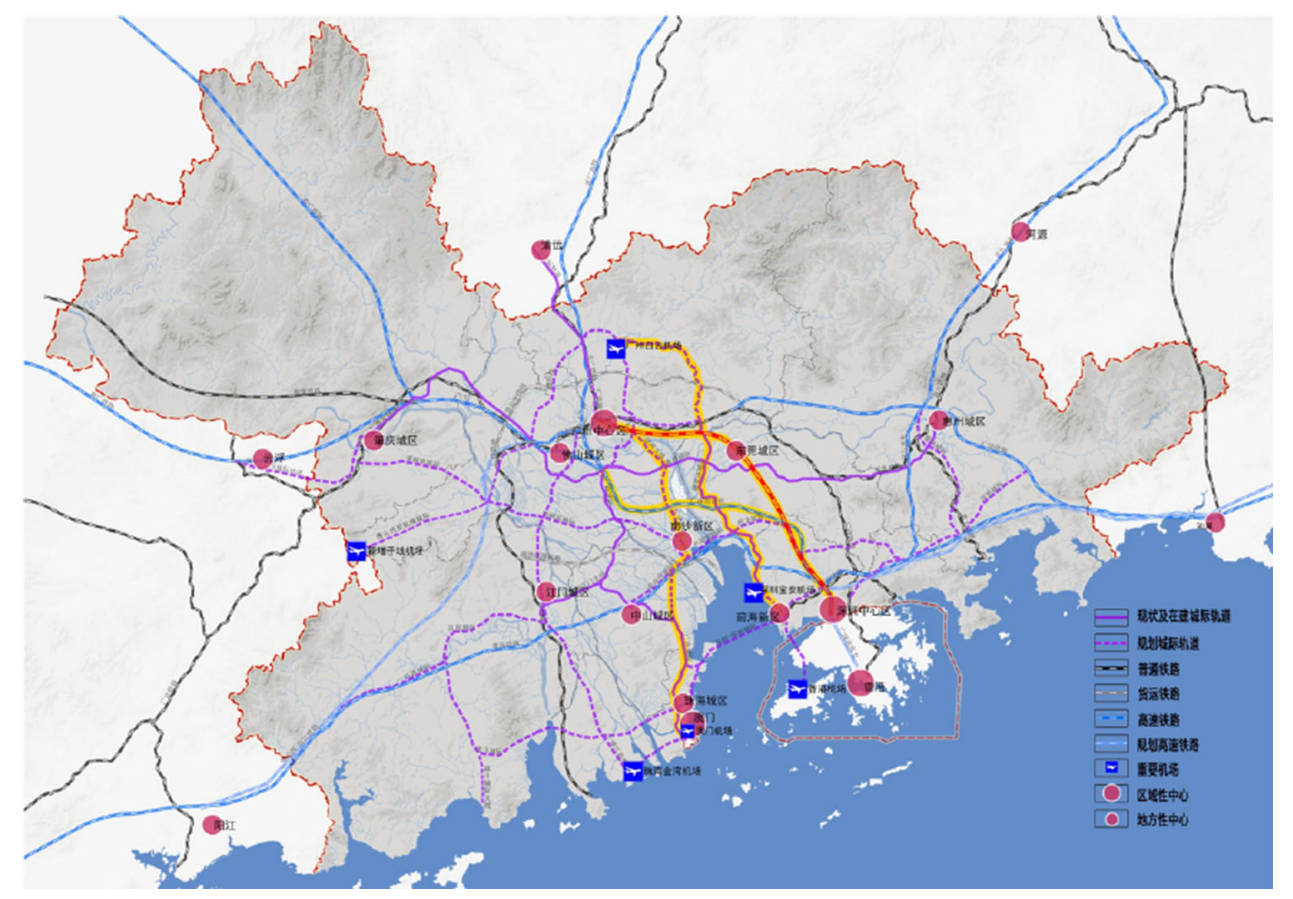

Higher-order centers should have higher levels of transport connection, to maximize the benefits of intercity railway in the PRD area, it is important to consider the following two principles:

1. Direct connection between high-level centers (public centers or business centers).

2. Make land use adjustment around transit stations and building transfer or commercial hubs.

\subsection{Regional Transit-Oriented Policy}

Land resources surrounding a rail station is a highly coveted asset that local governments have in their control, while the construction and sustainable operation of the intercity lines needs TOD (transit-oriented development) measures to capture the land value appreciation, which has been widely used in Japan and Hong Kong [4]. 


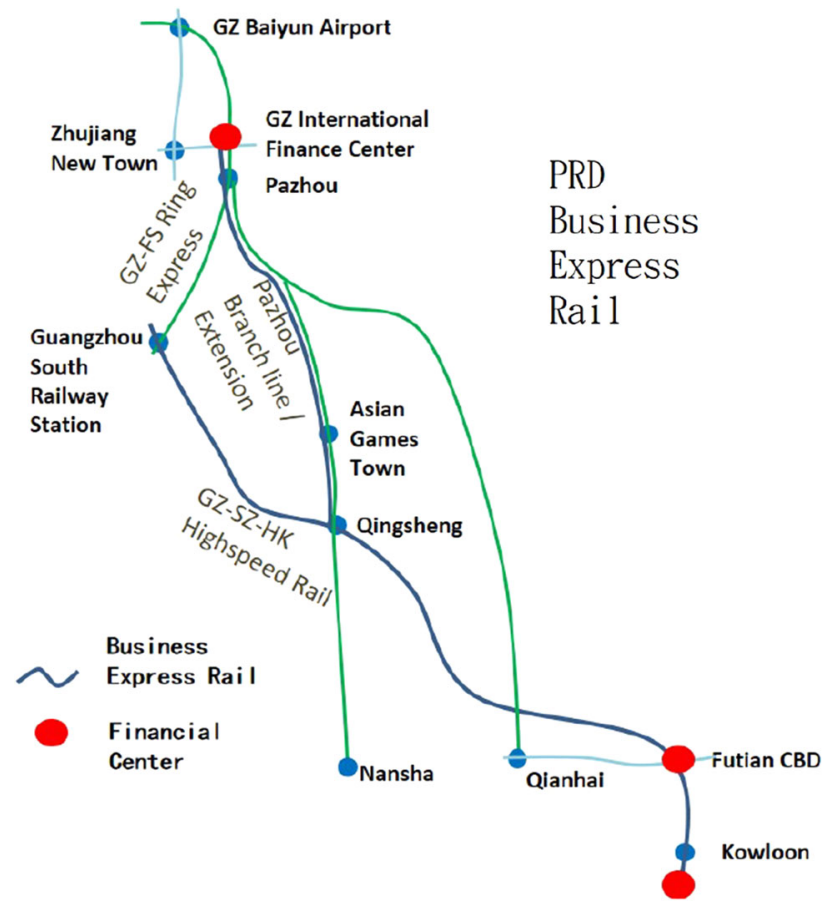

Fig. 14 PRD business express rail, connecting major financial centers

To reduce private car usage and support regional transit development, transit-oriented policy is needed for a better railway network. The following strategies are advocated:

1. Provide economic incentive for public transit usage. Limit the growth of private automobiles by using congestion pricing or parking charges to discourage private modes of transport. In addition, lower railway or transit prices to increase the transit ridership

2. Create a transit-oriented spatial development strategy. Incorporate a thorough planning and improve the design of mixed-use developments within 800 meter radius of railway stations with high density.

3. Build a seamless transfer network, improve the transit services. Establish a multilevel transit structure, for the eastern part of the PRD region, regional intercity rail and commuter rail constitute the main network, while in the less-developed western part of PRD, light-rail network and BRT system should also be considered

\subsection{Combined Rail and Subway System Network in PRD and System Integration}

The intercity railway of the PRD is still in its initial stage, and the integration with other railway systems such as the urban metro system or the national high-speed railways are desirable. The integration of these three systems will improve the operational efficiency and reduce transfer time between the lines. There is already a national railway on the intercity railway track from Zhuhai to Guilin.

Several measures could be used and better integration is proposed.

First, enhance the compatibility of different modes or railway cars. One of the limiting factors is the kind of railway cars being used. CRH6, the train that is designed to operate along the PRD intercity line is adapted from the China Railway High-speed (CRH) platform and is not as flexible as the subway express train, which can be run on other urban subway tracks and share the same station or fare system. The recently opened No. 11 express line of Shenzhen shares the same speed of the intercity lines (more than $100 \mathrm{~km} / \mathrm{h}$ ) but is an integral part of the subway systems.

Second, the combined operation of different railway companies. In the PRD, there are three different entities in charge of the operation of different rail networks; they are the national railway company, the PRD intercity railway company, and the municipal subway company for individual cities. The unification of different operations and the use of uniform transit cards are crucial for the public and should facilitate rail system integration.

\section{Future Work}

The problems and planning solutions of the regional railway network in the Pearl River Delta have been investigated. From Fig. 15, using GIS analysis, we can see the heat map of the railway network (plan, with all three systems) of the PRD, and the two railway dominated areas of Guangzhou and Shenzhen are illustrated with the deep purple color. For the railway to be more efficient, more

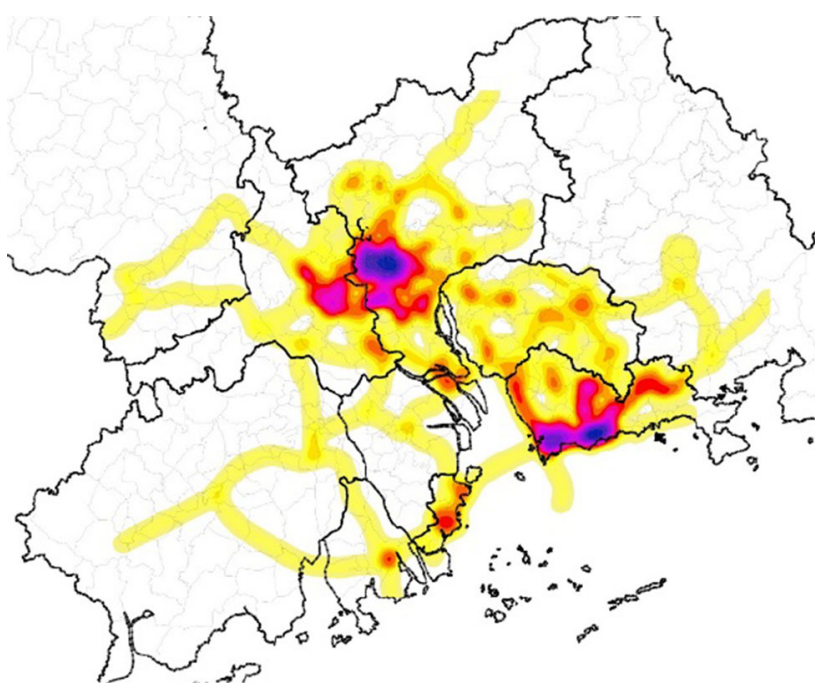

Fig. 15 Heat map of planned PRD railway network (including subways) 
effort is required to increase both the railway coverage and efficiency. The era of a sustainable and integrated railway system in the PRD is approaching and the future holds a lot of potential and promise.

In conclusion, further land use, railway network integration and synergy should be studied in order to promote a more sustainable and harmonious railway and urban development. Likewise, more data other than cell phone usage can be used for research; new methods such as big data and machine learning could be employed, so as to urge more data-driven analysis and better planning and informed decision making.

Open Access This article is distributed under the terms of the Creative Commons Attribution 4.0 International License (http://crea tivecommons.org/licenses/by/4.0/), which permits unrestricted use, distribution, and reproduction in any medium, provided you give appropriate credit to the original author(s) and the source, provide a link to the Creative Commons license, and indicate if changes were made.
Funding Funding was provided by Guangdong Provincial Government.

\section{References}

1. Guangdong Urban and Rural Planning and Design Institute (2016) Pearl River Delta Total Area Spatial Plan (2015-2020), Planning Document

2. Chinese Academy of Urban Planning and Design (2015) Pearl River Delta Comprehensive and Integrative Transportation System Planning, Planning Document

3. Ausubel JH, Marchetti C (1998) Toward green mobility: the evolution of transport. Eur Rev 6:137-156

4. Tsukada S, Kuranami C (1990) Value capture with integrated urban rail and land development: the Japanese experience and its applicability to developing countries. University of Sussex, PTRC transport and planning meeting, Brighton

5. Taylor PJ, Derudder B (2015) World city network: a global urban analysis. Routledge, New York 